Article

\title{
Digital Omotenashi: Toward a Smart Tourism Design Systems
}

\author{
Chaeyoung $\operatorname{Lim}^{1}$ (D), Noha Mostafa ${ }^{2}$ (D) and Jaehyun Park ${ }^{1, *}$ \\ 1 Department of Industrial Engineering and Economics, Tokyo Institute of Technology, Tokyo 152-8552, \\ Japan; lim.c.ad@m.titech.ac.jp \\ 2 Industrial Engineering Department, Zagazig University, Zagazig 44519, Egypt; namostafa@eng.zu.edu.eg \\ * Correspondence: park.j.ai@m.titech.ac.jp; Tel.: +81-3-5734-2589
}

Received: 31 October 2017; Accepted: 22 November 2017; Published: 25 November 2017

\begin{abstract}
The tourism industry is currently facing many challenges; one of the main challenges is the lack of having smart tourism systems that make use of the recent advances in information and communication technology. Another challenge is designing such smart tourism systems while embracing diversified tourists' sustainable values of experience (functional values, social values, emotional values, and epistemic values). In light of these challenges, the overall objective of this work is to design a smart tourism experience-centered system that considers social and technical perspectives. The Socio-Technical Systems theory was adopted as a theoretical foundation, and the Design Science Research methodology was used to develop a smart tourism system and a practical design artifact. A case study from the Japanese tourism context was studied by exploring tourists' sustainable values of experiences and local staffs' behaviors. The main problem was the dysfunctional communication between local service staffs and foreign tourists during the service process. After identifying the problem and the objectives, a relevant smart tourism system was synthesized and tested as a design artifact. The results of the utility test of the proposed artifact showed its effectiveness and efficiency in facilitating the service process and in creating multi-dimensional values of experience.
\end{abstract}

Keywords: smart tourism; mobile applications; design science; information systems; case study; sustainable values; Japanese tourism; omotenashi

\section{Introduction}

Over the decades, Information Technology (IT) has been served as a catalyst for innovations in tourism. Since the early eTourism studies [1], Information Systems (IS) have contributed in rationalizing tourism information and tourists' behaviors-through websites that enable reservation and price comparisons (e.g., Expedia and Booking) and websites that provide information, reviews and recommendations (e.g., Tripadvisor and WikiTravel). Recently, smart tourism studies have attracted the interest of many scholars [2,3], and they have addressed the importance of big data-driven approaches for user-friendly, customized, and intelligent tourism systems [4,5]. By highlighting the role of IS as a tool for supporting tourists during their travels, smart tourism studies have the potential to make many achievements, particularly in promoting travel planning systems, or what we are calling "Proactive Tourism Systems". For instance, big data-driven approaches can facilitate the travel systems to collect, analyze, learn and predict users' preferences and behavioral patterns; and help the system to be more proactive- by providing more relevant and personalized information and suggestions for the travelers. However, those endeavors still face many limitations.

First, there is a lack of attention on embracing diversified tourists' sustainable values of tourism experience. Substantial numbers of tourism studies found that tourists often consider and go for 
disorganized choices during their travel, which is partially due to the paradigm changes of their values of experience-from a single functional value to multi-dimensional values (i.e., social values, emotional values, and epistemic values). Hence, smart tourism studies should stress managerial values and functional values-optimization, standardization, rationalization of information, interaction, prediction of tourists' behavioral patterns, etc. $[1,2,6]$.

Second, even though many claims have been made for embracing tourists' experiences in tourism systems [7-10], only few studies have proposed relevant design methods and empirical case studies that provide a sustainable tourism experience. With this respect, a perspective of the Socio-Technical Systems (STS) theory $[11,12]$ can provide considerable ideas for designing experience-centered tourism systems by: (1) embracing multiple stakeholders and subsystems (i.e., social subsystems, technical subsystems, and environmental subsystems); and (2) empowering responsible autonomy of information systems to establish and operate successful, sustainable, and smart tourism systems.

In light of these endeavors and limitations, this work puts forward two research questions:

(RQ1) How should experience-centered tourism systems be designed?

(RQ2) Which aspects of the Socio-Technical systems theory can be used to support efficient, sustainable, and smart tourism systems?

Based on the STS perspective, this study aims to explore and propose a design framework for smart and sustainable tourism systems. To evaluate this, a design science-based tourism application called "Digital Omotenashi" was conducted, referring to the Japanese tourism context. During the development phase, a tourist mobile application called "EATJOY" is synthesized. The application helps to revive the famous Japanese "Omotenashi" culture which means "Japanese style of providing hospitality", as the authors and the Japanese tourism industry believe in this concept as a key potential factor in improving the performance of the tourism industry.

The contribution of this study is threefold. First, it proposes an effective tourism design framework and artifact that empowers local culture, by jointly optimizing technical, social, and environmental subsystems. Second, it highlights the potential employment of IS in tourism by developing tourist-friendly application that supports communication, decisions, and cultural aspects. Third, the synthesized design artifact "EATJOY" focuses on multiple-user aspects and surroundings, and can be a base for further designs of smart tourism systems.

The paper is organized as follows: In Section 2, a literature review is given on smart tourism, tourists' sustainable values, and the use of IS-based design models for tourism. In Section 3, the theoretical foundation of this work is discussed and elaborated to develop a proposed model for smart tourism systems. Section 4 gives the methodology followed in this work. Section 5 describes the case study of this work, the "Digital Omotenashi project", and the proposed design artifact for a smart tourism system. Contributions and implications are given in Section 6. Finally, limitations and future research directions are given in Section 7.

\section{Literature Review}

In this section, a review is given for the previous works on smart tourism, the concepts of value of experience, and the use of IS in tourism systems. This relevant scope of literature helps to explore successful and sustainable IS design approaches that can satisfy user values in the dynamic tourism environment.

\subsection{Smart Tourism}

Over the decades, significant changes have been achieved in tourism. At the center of these changes, there have been multiple advances in Information and Communication Technology (ICT) which motivate researchers and practitioners to use it to design innovative tourism systems. Since the late 1990s, studies on eTourism have emerged with focusing on designing information structures and interfaces for managers and users. Based on the technological features of ICT, prior studies 
highlighted the use of IS to develop effective and efficient models to propagate, match, and share the useful and relevant information among technical infrastructures and social communities [1,2]. Reservation systems and review platforms are good examples of this paradigm [13,14]. By using these designated systems, tourists can access all the information relevant to the desired destination easily and instantly. Such systems motivate the users (tourists) to change their behaviors and their consumption patterns. For instance, currently, an increasing number of tourists prefer to have self-organized travel plans by using the Internet based on their preferences and financial capacity rather than to follow packaged tour plans [1].

More recently, there has been a paradigm shift in tourism towards more user-friendly intelligent systems based on big data analysis, or what can be called "smart tourism" [2,3,15]. In the literature, scholars have discussed the concept of smart tourism systems; it can be seen that this concept is still broad and fuzzy, but primarily discussed in the scope of: (1) mutual interconnection and synchronization between technology and systems; (2) customized systems based on intelligent analysis of big data; (3) integration of tourist's experience with physical and digital environment; and (4) facilitating tourism ecosystems by means of information sharing. Intelligent recommendation systems can be seen as representative cases of smart tourism systems [2]. Paradoxically, some tourists find difficulty in making their travel decisions due to the excessive amount of information [1]. Hence, the smart tourism system should help the tourists to easily make their decisions before or during their trips, by providing them with relevant and meaningful information, based on big data analysis, personal information, behavior patterns, etc. $[2,15,16]$. To sum up, the smart tourism paradigm can achieve significant contribution in transforming tourism systems to be more proactive by supporting the tourist decision-making process by providing tailored-made suggestions.

\subsection{Tourists' Sustainable Values in Smart Tourism}

In recent tourism literature, a new phenomenon was found in the behavior of tourists: many tourists prefer "values of experience" to "value for money" $[17,18]$. Interestingly, the tourist tends to make a choice that may be relatively unplanned and disorganized, if this choice is related to an experience that matches his personal values [16]. For instance, plenty of tourists make quick tour decisions to have an authentic experience (e.g., social and cultural identities, traditions, memories, food, local peculiarities, and rural landscape) with chances of being involved in various activities to satisfy their own sustainable values $[15,17]$. This phenomenon suggests that tourists tend to set and expect higher and more diversified values for tourism experience. Thus, the challenge is how to design a tourism system and a relevant ecosystem that can support these diversified and varying values. Designing such systems can potentially be linked to post-satisfaction and the intention of revisiting the tourism venue $[19,20]$ as well as adaptive tourism ecosystems that enable diversified and varying tourists' values [21].

However, optimizing tourists' diversified values in their tourism experience is a fastidious issue, as the process and values are inherently personal. Previous studies argued that the value of experience only exists in the mind of each of person based on his character and background (i.e., emotional, physical, intellectual and spiritual) [15,22]. In terms of value of experience, prior marketing studies found two main folds in product and service experience, albeit in a qualitative way: economic-utility dimension and socio-psychological dimension [23]. The former dimension stands for functional attributes (e.g., perceived price, quality, benefits and risk) of products and services [24,25]; the latter dimension represents aspects of higher order abstractions (e.g., prestige, social interaction, novelty and hedonism) [26,27]. Based on this conceptualization, Sheth et al. [28] proposed five elements of consumption values that affect consumer choices and behavior: functional, social, emotional, epistemic, and conditional values. More recently, Williams and Soutar [23] specified four applicable elements in tourism experience context from the original framework-functional, social, emotional, and epistemic values. Definitions and examples on each value are discussed as follows: 
Functional value is defined as "perceived utility acquired from an alternative's capacity for the functional, utilitarian or physical performance". Previous studies found that the "expected" functional values can influence individual's decisions and evaluation. Examples on these functional values may include seat comfort, drinks, lunch stops, tour commentary, etc.

Social value is defined as "perceived utility acquired from an alternative's association with one or more specific social groups". Previous studies found that tourists get affected by the opinion of social groups toward the choice of types of tourism products, brands, and retail service settings.

Emotional value is defined as "the ability of the product or service to arouse feelings or affective states". Prior studies found association among various emotions (e.g., pleasurable emotions), evaluation of tourism service quality, and post-consumption.

Epistemic value is defined as "the perceived utility acquired when the product arouses curiosity, provides novelty, and/or satisfies a desire for knowledge". Previous studies found the evident influence of epistemic values on people's choices and afterward satisfactions.

Previous IS studies suggest that perceived value is key motivation of system use; and it has to be identified and satisfied for end users, service providers, and stakeholders for sustainable usage $[29,30]$. Therefore, this paper addresses these four value dimensions [23], and will provide a structure to observe the sustainable values of tourist's experience, and to deal with one functional value to multi-dimensional values.

\subsection{Using IS for Smart Tourism Systems Design}

In earlier studies on eTourism, scholars have discussed the potential of using IS as a mediator between technology and tourism, which can enrich the tourism experience. The scholars argued that the future eTourism systems should deal with the various motivations and desires of tourists [1]. In more recent studies, tourism communities also suggested using IS for creating smart experience, connecting ICT with tourism experience [3], and improving the experience of tourists as well as the competitiveness of tourism organizations [14]. However, only few studies have deeply discussed these issues. Buhalis and Amaranggana [15] proposed a personalized design of tourism products and services that can satisfy the unique needs and preferences of each visitor. Chung, Koo and Lee [16] showed the potential of the recommendation services that influence tourists' unplanned behavior. This small number of studies exhibits a clear research gap. More works are needed to elaborate the use of IS to develop smart tourism systems with taking the values of experience into consideration.

Although there are a few studies on tourists' behaviors and desires, current tourism studies do not provide relevant knowledge and applications on the tourists' sustainable values of experience in the context of smart tourism. Therefore, in this study, we argue the importance of designing smart tourism systems that highlight tourists' sustainable values of experience and capture their latent values and requirements in their trip.

\section{Theoretical Foundation}

In this paper, the Socio-Technical Systems (STS) theory $[11,12]$ is invited as a theoretical foundation. From the literature review, the social aspects are essential in determining the tourists' sustainable values [23]. In this respect, a perspective of the Socio-technical Systems (STS) theory can provide a considerable understanding of the values of experience; this understanding would help the designer to develop a Smart Tourism Design (STD).

\subsection{The Socio-Technical Systems (STS) Theory}

Tourism experience is made up of interactions amongst various stakeholders, infrastructures, and environment. However, previous smart tourism studies fairly focused on the technological and managerial aspects in tourism. For instance, most studies argued the adaptation, connection, and utilization of technology per se or the relevant infrastructures (i.e., internet, smart city infrastructures, etc.) $[3,6,31]$ or rationalized using information for organizations or increasing 
destination competitiveness (i.e., efficiency, cost management, etc.) [3,32]. Moreover, Even though service practitioners are among the primary stakeholders who deliver services and cultural experiences for the tourists, there has been lack of attention on embracing their problems, needs, and values into the tourism systems [2,33]. Instead, many of the tourism systems have been developed in a way that makes tourists skip the interaction with other stakeholders, such as full-automated service systems [34] or information kiosks [35]. In this regard, STS perspective suggests a smart tourism design opportunity that enables the joint-optimization of various subsystems, such as social subsystems, technical subsystems, and environmental subsystems [11,12,36]. With the objective of finding balanced values for all of those systems, there can be an increasing possibility of having efficient STD applications that support more synergetic values from stakeholders and the interconnected subsystems $[37,38]$; such objective is a primary goal of smart tourism systems.

As discussed in the previous section, tourists' values for tourism experiences have been diversified, and are still evolving. Simply optimizing, codifying and practicing the current best value blend may not work for the future tourists. In this regard, the STS perspective suggests empowering responsible autonomy of stakeholders [39]. By targeting better social values (i.e., quality of work life and labor satisfaction), the tourism organization can achieve higher performance, responsible autonomy, and adaptability towards complexity and transformative external environment [12,39].

Hence to design experience-centered tourism applications, smart tourism design should consider: (1) joint-optimization view of subsystems; and (2) social and diverse perspectives. Pursuing a holistic approach for system design that embrace technological, social subsystems, and environmental subsystems can add values to the tourism system. In addition, this STD should take into consideration problem-solving and social values for various stakeholders; these aspects can enable the system to attain vitality towards the complex and changing environments in tourism.

\subsection{A smart Tourism Design Based on the STS Theory}

Based on the STS theory and the previous smart tourism studies, a proposed Smart Tourism Design model (STD model) is synthesized (see Figure 1).

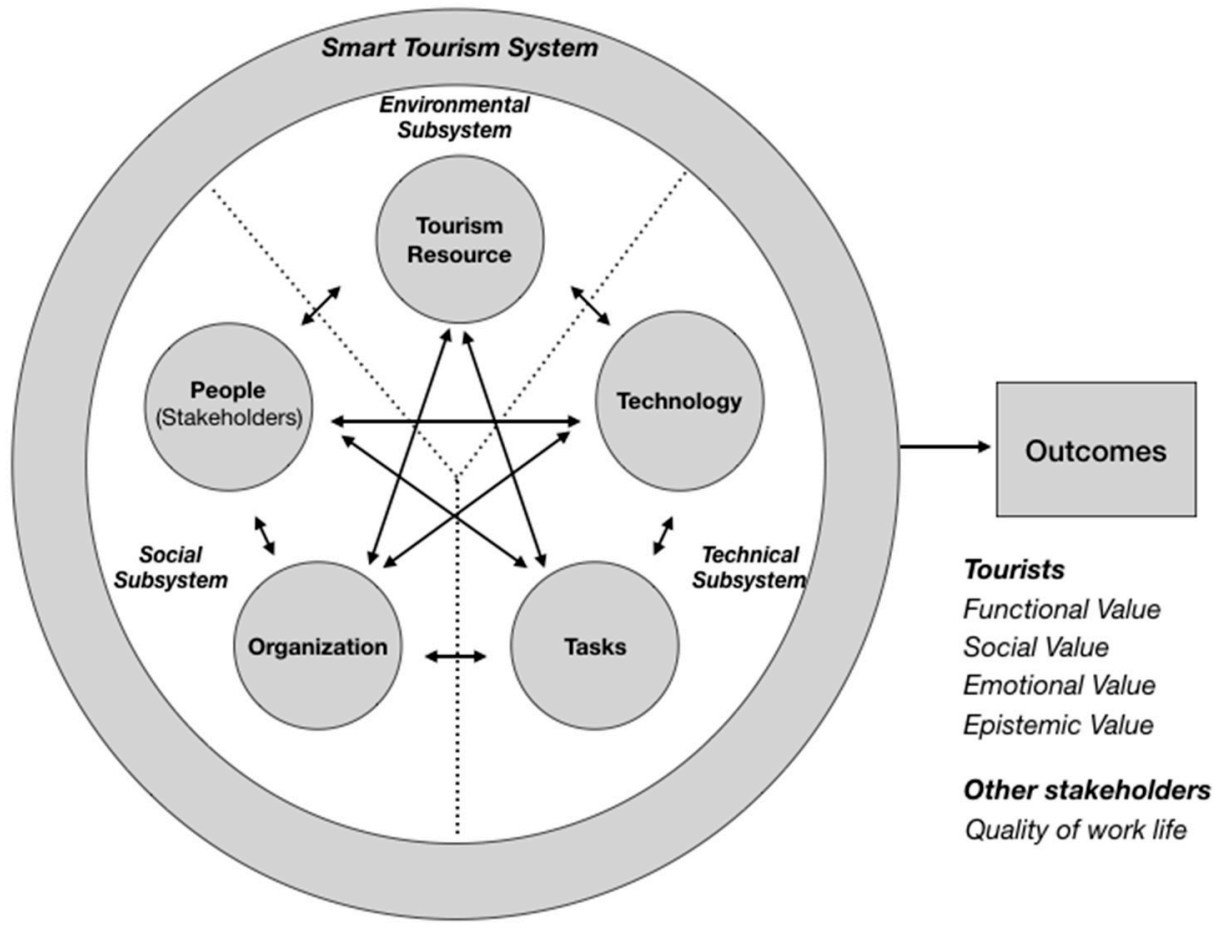

Figure 1. A Proposed Smart Tourism Design Model. 
The model consists of designable elements (subsystems), interactions, and evaluative outcomes. The objective of driving each cycle is to incrementally achieve deeper comprehension of the relationships among people, organization, tourism resources, tasks, and technology in the context of tourism. It highlights two design principles from the STS theory: (1) building synergy and sustainability in smart tourism systems; and (2) forming diversified values for multiple stakeholders in tourism.

Thus, the model highlights clarification, utilization, and connection of available elements, interaction, and possible synergy effects in tourism, when designing the system. This STD model can assist the designer to easily clarify and apprehend core issues and their relations in targeting the problems (in the ideation phase). In addition, it can help designers to be unbiased to one of the subsystems, but to approach them in a comprehensive and harmonized way to build a synergetic and sustainably-used smart tourism design applications and services. Based on this STD model, we conducted a smart tourism design project. In the next section, the design science research methodology is explained and a discussion is given on the application of the STD model can be achieved into our smart tourism design project.

\section{Methodology}

This study follows the Design Science Research (DSR) as a research methodology in order to address a complex problem by developing and investigating the utility of the proposed solution artifacts [40]. Thus, the cyclic process of the DSR suggested by Peffers et al. [41] was followed along with Hevner and coworkers' framework guidance [42].

According to Peffers et al. [41], The DSR process consists of the following processes-problem identification, defining objective of solution, design and development, demonstration and evaluation, and communication. The substance and objective of each cycles are as follows:

Problem Identification and Motivation: Defining the specific research problem and justifying the value of the solution are the main purposes of this phase. During this phase, researchers can understand the specific problems and gain a deeper comprehension towards the complexity of their nature.

Defining Objective of Solution: In this phase, the main purpose is to define the objective of the design that will be proposed for solving the problem. Through this phase, researchers can determine the desired features and functionality of the proposed design artifact.

Design and Development: In this phase, the primary goal is to develop the design concept and an actual artifact. This phase includes determining the viable functionality and features in designing the IS, creating the systems prototypes with practical design concepts for further evaluation stages.

Demonstration and Evaluation: In this phase, the primary goal is to demonstrate, observe and measure how well the artifact provides a solution to the problem. Previous studies described relevant actions of this phase: reflecting design principle (demonstration); providing the effective knowledge of how to use the artifact to solve the problem (demonstration); and achieving empirical evidence or logical proof of the artifact's efficiency in solving the problem (evaluation). Based on the outcome of this phase, researchers can decide whether to repeat one of the former phases to improve the effectiveness and efficiency of the artifact or to proceed to the communication phase.

Communication: In this phase, the primary object is to communicate the problem and the designed artifact to the researchers and relevant audience. By doing this step, researchers can contribute to both practice (i.e., propagating the problem solution) and design theory (i.e., adding an instantiation of design model and theory) and attain feedbacks and suggestions for further artifact improvement.

The DSR methodology was applied to design the proposed smart tourism project. The detailed process is explained in Section 5. 


\section{A Case Study of Smart Tourism Design (STD)}

We conducted a smart tourism design case study called "The Digital Omotenashi Project" as a relevant case, because it explores tourists' sustainable values and experiences and synthesizes a relevant STD application.

\subsection{Project Background}

The Japanese government has paid great attention to cultivate the Japanese tourism industry. Recently, as the country is going to host the 2020 Olympic games in Tokyo [43], the tourism industry encounters a critical situation that requires a more innovative tourism system that can deal with the expected number of tourists. During the meeting of the International Olympic Committee (IOC) in 2014, they strongly highlighted a traditional Japanese cultural concept called "Omotenashi". This concept means that local people (from residents to service staff) naturally provide high quality of services to the foreign tourists as if they are hosts who serve invited guests in their own house, since they traditionally consider providing such good deeds as karma (reward for the deeds of a former life). Thus, the Japanese marketing researchers expected that this culture can boost the quality of service $[44,45]$, or what they called "the Omotenashi effect".

Contrary to their expectations, the Omotenashi culture did not show a significant effect on the service quality to foreign tourists, although it shows such effect when dealing with the local customers. Due to the lack of confidence and capability in using foreign languages, local Japanese people feel uncomfortable when interacting with foreign tourists. These individual and mass behaviors tend to inhibit the basic service qualities. As a matter of fact, foreign tourists currently suffer from various service difficulties (e.g., low service quality, service conflictions, service denial) which have negative impact on the tourist's satisfaction [46]. Therefore, the goal of the "Digital Omotenashi project" is to propose innovative business design by exploring the users, environment and its context. Figure 2 depicts the DSR phases adopted for the Digital Omotenashi project. In the next section, each phase is illustrated and elaborated for the proposed STD project in a detailed manner.

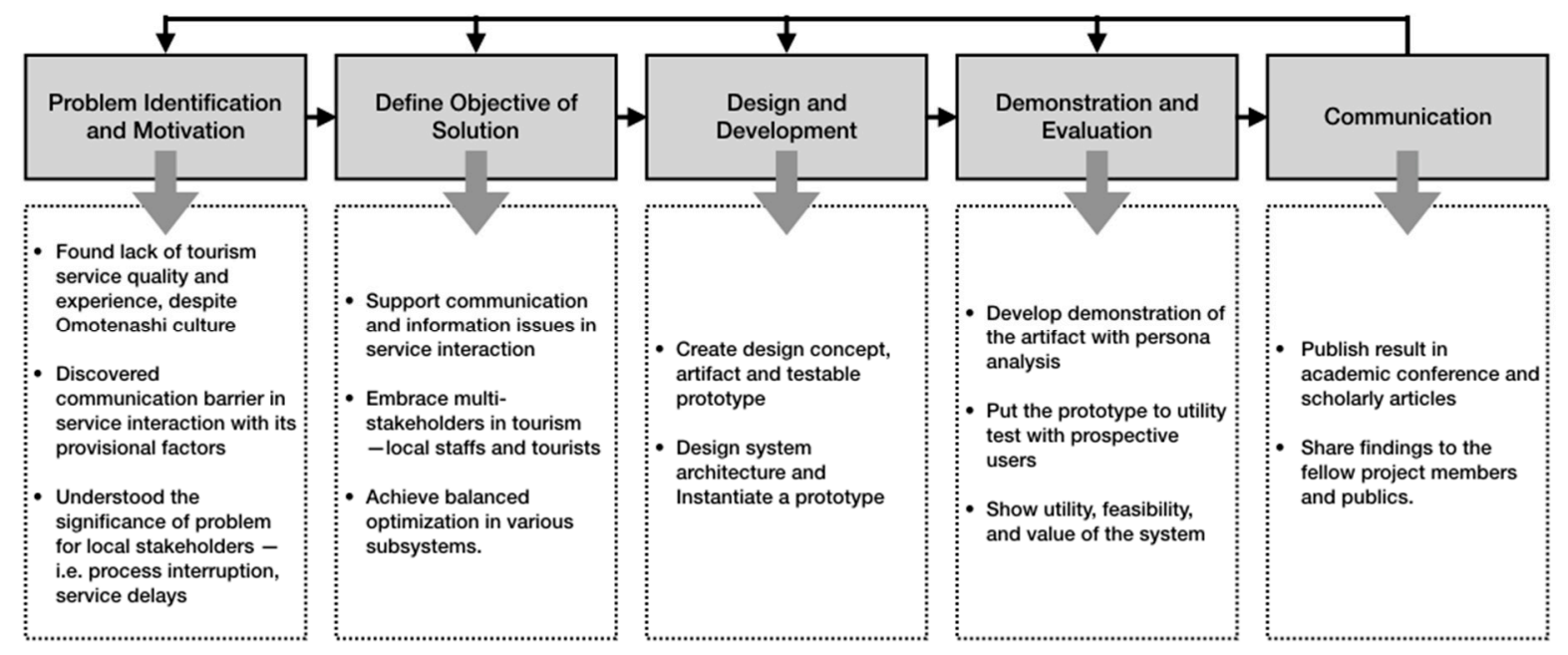

Figure 2. Smart Tourism Design Project by using Design Science Research Methodology.

\subsection{Phases of the STD Project by Following the DSR Methodology}

Figure 2 demonstrates how we conducted a case of smart tourism design project by following the five phases of the DSR methodology: 


\subsubsection{Problem Identification and Motivation}

This phase was iterated for two rounds-the first round is for understanding the nature of the problems and exploring them, and the second round is for specifying the problems and validating them.

In the first round, the project started with two general design inquires:

(1) Who are the main stakeholders in tourism service operation in Japan?

(2) What kinds of problems do these stakeholders deal with during interactions, particularly when foreign tourists request the service?

Based on these inquiries, unstructured observations (10 min each) and interviews (10 min each) were conducted on site. Focusing on identifying the key stakeholders and interactions amongst the subjects, the project team visited 22 restaurants in Shibuya area, Tokyo, Japan. This area was selected as it is one of the main tourist destinations in Tokyo, with many attractions and entertainment spots. Figure 3 show photos from the team's discussion sessions after visiting the study field.
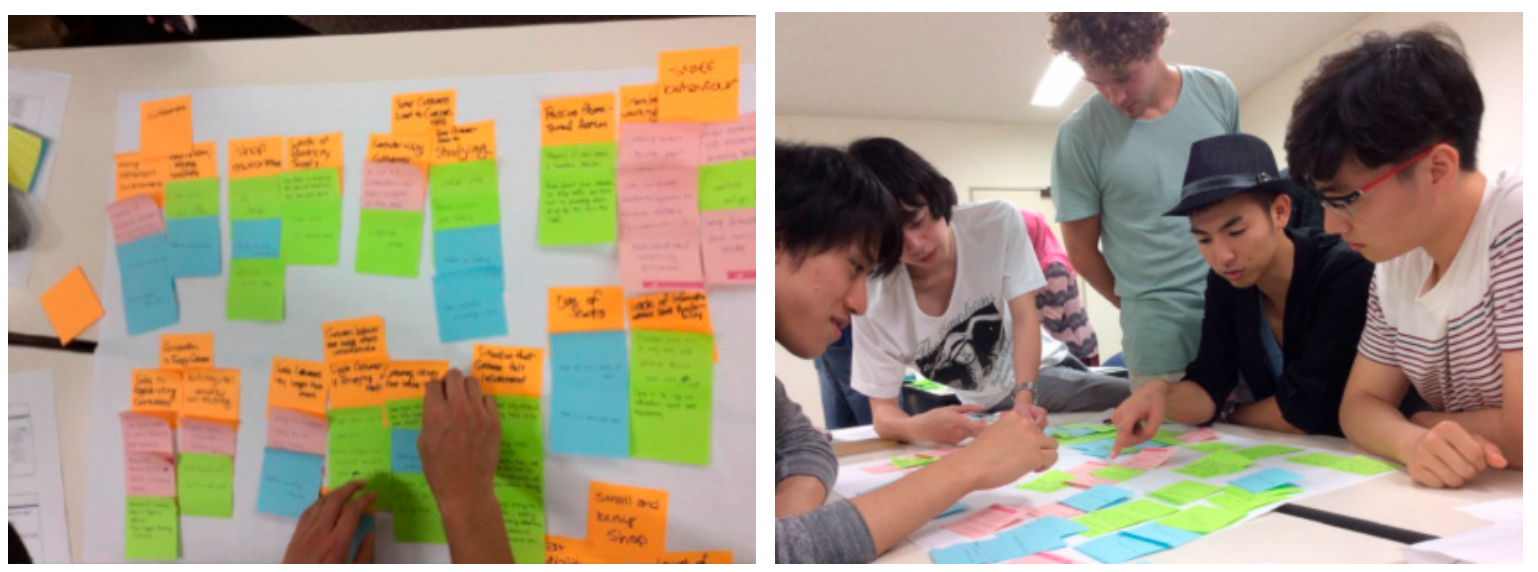

Figure 3. Data Analysis from fieldwork.

In the study field, three different stakeholders with distinctive interests were clarified-foreign tourists, service providers, and service owners. The team could find some communication barriers between the Japanese staff and foreign tourists caused by the limited language proficiency from both sides. Even though there are strict service standards and codified behaviors in those local restaurants, the staff could not provide equivalent level of service quality towards foreign tourists, represented in uncommon facial expressions, missing smiles, and lack of explanations on the requested service. Most stores leave such dysfunctional communication as it stands, and few of them utilize temporal solutions, such as English menus and more expressive body language.

The second round starts with more specific design inquiries as follows:

(1) What kinds of conceptual problems can be defined in the communication between foreign tourists and service staffs?

(2) What is the negative outcome resulting from the current problems?

(3) What are the proposed solutions against the current problems?

Based on these inquiries, longer semi-structured observations in two international cafés and two local ramen restaurants were conducted. The project team expected that comparing these two types in the study field can provide some insights; as such, stores generally have distinctive approaches in service trainings and strict guidelines for service staffs to deal with foreign customers.

From the observations, two key factors were found to bring problems about and lead to negative outcomes; language factor and emotional factor between service staffs and tourists. For instance, 
service staffs in both restaurants displayed tendency to avoid direct communication with the tourists in more obvious form of their service behaviors; those staffs delayed their responses or stuttered during the conversations even in their local languages. The staffs in the cafés could complete receiving foreign customers' orders, eventually, by utilizing their trained basic language skills or by using effective body languages (e.g., raising relevant objects or pointing to images in the menus or screens). On the other hand, in one of the ramen restaurant, the staff called some of their colleagues to receive language assistance, since they could not deal with the foreign tourists on their own; as a result, longer service delays and process interruptions on the entire service were made.

Interestingly, the staff in the other ramen restaurant could treat foreign customer in effective way. That is due to the existence of vending machines (VM) in the store, which limit the direct communication between the staff and the tourists. In the interaction process, the tourists are asked to select from the menu and finish their payment in advance by the machine to receive their orders. Therefore, the staff could provide constant quality of service to the tourists without stress.

On the other hand, the emotional pressure on the tourists was also observed. For instance, the tourists were hesitant to enter the restaurant; they tended to decide on easy and obvious choices in a short time to avoid uncomfortable situation. They could not receive enough promotional services (e.g., free provision of rice and toppings) or cultural instructions (e.g., seasonal menu, cultural guidance by the staff) in detail. For example, in Japan, making sound during eating the food is a traditional etiquette of customers, exclusively in ramen restaurants, to show the respect and satisfaction toward the staff and that the customer likes the taste of food. However, foreign tourists were silently eating ramen as they do in other restaurants.

\subsubsection{Define Objective of Solution}

This phase was iterated for two rounds based on the principles of the STD model一the first round focuses on the ideation of the design. The second round focuses on fine tuning the objectives of the systems amongst various subsystems and towards a real tourism context. Table 1 gives an anatomy of the identified issues for smart tourism design application in the technical, social, and environmental subsystems with the expected outcome of the STS-based design model.

In the first round, the project team started to classify the problems, circumstances and associations through the lens of the STD design model (see Table 1). Based on the mapped issues, the project set three primary objectives of the initial system design:

(1) Design tourism system that support service communication and information issues to satisfy the values of experience for tourists and the work values for local staffs.

(2) Design tourism system that embrace the needs, problems, and circumstances of the different stakeholders.

(3) Design tourism system that can optimize the coordination amongst various subsystem for ultimately maximizing the synergies and total value in tourism.

In the second round, based on the utility test of the first design prototype, the team set the objectives as follows:

(1) Improve the design concept of tourism systems that maximizes value for tourists and stakeholders.

(2) Improve design concept of tourism system that generates more synergy between subsystems and fits well into real context. 
Table 1. Identified Design Issues for a Smart Tourism Design Application.

\begin{tabular}{|c|c|}
\hline \multicolumn{2}{|l|}{ Technical subsystems } \\
\hline $\begin{array}{l}\text { Technology } \\
\text { Lack of digital technology integration, coordination } \\
\text { between tourism stakeholders }\end{array}$ & $\begin{array}{l}\text { Local restaurants } \\
\text { - } \quad \text { none or unintegrated digital technology (i.e., analog or digital POS } \\
\text { with paper-based menu) } \\
\text { - } \quad \text { stopgap technology (i.e., vending machine) } \\
\text { Tourists } \\
\text { - Internet and mobile technology for searching information } \\
\text { - Web-based language translators }\end{array}$ \\
\hline $\begin{array}{l}\text { Task } \\
\text { Lack of systematic support for tourism service } \\
\text { interaction between local staff and foreign tourists }\end{array}$ & $\begin{array}{l}\text { Local restaurants } \\
\text { - } \quad \text { Service delay, process interruption } \\
\text { - } \quad \text { Unmanaged service quality for foreign tourists } \\
\text { - Lack of utilizing stopgap behaviors (i.e., effective body languages) } \\
\text { Tourists } \\
\text { - Lack of relevant service information (i.e., local information, } \\
\text { - } \quad \text { Lack of cultural instruction }\end{array}$ \\
\hline \multicolumn{2}{|l|}{ Social subsystems } \\
\hline $\begin{array}{l}\text { People } \\
\text { Restricted interactions and outcomes of service } \\
\text { and tourism due to dysfunctional communication }\end{array}$ & $\begin{array}{l}\text { Local restaurants } \\
\text { - } \quad \text { Lack of service language capability } \\
\text { - Emotional pressure and fears toward communication with } \\
\text { foreign tourists } \\
\text { Tourists } \\
\text { - Emotional pressure and fears toward communication with local } \\
\text { staffs, interrupting service operation } \\
\text { - Restricted tourism experience (i.e., lack of interaction } \\
\text { and instructions with the culture or cultural subjects) }\end{array}$ \\
\hline $\begin{array}{l}\text { Organization } \\
\text { organizational neglect of tourism service problems } \\
\text { hindering the tourism potentiality }\end{array}$ & $\begin{array}{l}\text { Local restaurants } \\
\text { - Interested in achieving foreign customers, but concerning about } \\
\text { degrading service quality for local customers (e.g., some service } \\
\text { rejections for foreign tourists) } \\
\text { Neglecting the problems; sticking with the present stopgap } \\
\text { behaviors (i.e., vending machines), as the cost of training or } \\
\text { digitalization is too high for local stores. } \\
\text { Tourists } \\
\text { - } \quad \mathrm{n} / \mathrm{a}\end{array}$ \\
\hline \multicolumn{2}{|l|}{ Environmental subsystems } \\
\hline $\begin{array}{l}\text { Tourism resources } \\
\text { Lack of utilizing existing tourism resources }\end{array}$ & $\begin{array}{l}\text { Local restaurants } \\
\text { - Competent management capability of the service process } \\
\text { and quality } \\
\text { - Potential of Japanese Omotenashi culture } \\
\text { Tourists } \\
\text { - } \quad \mathrm{n} / \mathrm{a}\end{array}$ \\
\hline \multicolumn{2}{|l|}{ Outcomes } \\
\hline Value for experience/Quality of work life & $\begin{array}{l}\text { Local restaurants } \\
\text { - Most systems of stores do not consider the value for experience; } \\
\text { only some stores provided limited degree of functional values } \\
\text { - Staffs' emotional fears and pressures may be harming the quality } \\
\text { of work life } \\
\text { Tourists } \\
\text { - Starting with some degree of epistemic value, but due to lack of } \\
\text { communication and support from system, the other values could } \\
\text { not be maximized. } \\
\text { - Getting rid of service interaction by vending machine was harming } \\
\text { the other values of experience, except functional value. }\end{array}$ \\
\hline
\end{tabular}

\subsubsection{Design and Development}

This phase was conducted in two rounds: the first round is to determine and synthesize the initial design concepts; and the second round is to improve these design concepts and making a balance between the design prototype and the real tourism context, based on the results of the utility test. 
In the first round, based on the objectives set in the previous phase, the project team determined core functionality and features through a design artifact named "EATJOY". The design of EATJOY is based on a customized vending machine metaphor which mainly assists service order, communication, and relevant informational actions for both local staffs and foreign tourists in a form of mobile application. Then, the primitive form of prototype was developed for further utility tests in the evaluation phase by using MS PowerPoint.

In the second round, based on the feedback from the users in the first utility test, the project team made a reconfiguration to the initial design concept as follows:

(1) Full technology mediation to assist in interaction: Through the utility test, some unexpected issues were found, in both social and technical senses. In the social sense, tourists were, in fact, regarding interaction with local staffs as one of the important channels of cultural experience during their travel, even if it is a short interaction. In the technical sense, integrating new design concept to various types of the traditional serving system requires large efforts and costs, which may be burdensome for small local stores. Thus, the team decided to change the design concept from a "full technology interaction" to a "technology-assisted interaction' with employing the users" body language.

(2) Improvement of IS functions: In the study field, two issues related to informational actions were found; several foreign tourists expressed their desire to gain know-how and information about local restaurants, and they also expressed the difficulties they face in matching the web search result with the store signs written in Japanese and Chinese characters. Thus, some improvements in the interface were made in the design concept, such as sharing reviews and scores from local people, and image provision and recognition of store signs by using mobile devices.

(3) Extension to a decision-support application: Numerous tourists complained from difficulties in making decisions on visiting restaurant in limited time and budget, especially when they are in large groups. Some stopgap behaviors were found, such as having rules to follow the decision of the group's leader, or doing coin tossing. The project team decided to embrace these activities in the application design.

(4) Extension to a cultural instructive application: Most tourists expressed their desire to receive some instructions about what they are experiencing. Particularly, there was lack of means for them to attain such instructions when they are away from the official tourist attractions but in local sites (e.g., local restaurants).

The project team developed an advanced form of prototype by using Axure RP Team Edition 8.0 (Axure Software Solutions, San Diego, CA, USA). This software allows creating interactive prototypes of mobile applications with designed functionality and features, which can be tested with the users with mobile applications in various contexts.

EATJOY is an interactive mobile application and platform to be used by foreign tourists and local staffs in Japan, and it supports four main activities for foreign tourists: (1) Searching; (2) Decision-making; (3) Communicating; and (4) Understanding. Figure 4 depicts the Information Structure (IA) of EATJOY, it can be seen that it has ten main menus that cover the main features and functions of the application. Figure 5 shows the main screens of the application for the tourist and for the local staff.

(1) Searching: The application provides several useful channels and information to help the tourist to discover and reach the local restaurants. For instance, tourists can search for restaurants in any area by choosing the category of food, keywords and locations preferences. They can reach the site by using recognitions of image (store signs) and Quick Response (QR) codes attached at the store front.

(2) Decision-making: The application offers tailored suggestions to the tourists in a form of amusing game. In the function, the tourists can receive five series of restaurant suggestions (arranged 
based on the current location and preference of tourists) with pitching coin tossing game, they can joyfully reduce their efforts in searching and making decisions.

(3) Communicating: The application provides an interactive visual menu in foreign language. The menu has similar visual appearance and work process with analog VMs. Thus, the tourists can order food and drinks easily like they are already doing it with the analog VMs. Then they can hand over their device that progressed to the order contents screen, written in local language, to the local staff. Through these actions, the tourists can deliver their order and express their preference with body language. The local staffs can easily understand what tourists want and avoid misunderstanding through checking the translated order contents on the screen.

(4) Understanding: After a few seconds of the ordering process, the application automatically displays the story-telling screens to the tourists. The screen contains cultural explanations (e.g., etiquette, origins) and interesting stories related to the food and the region.

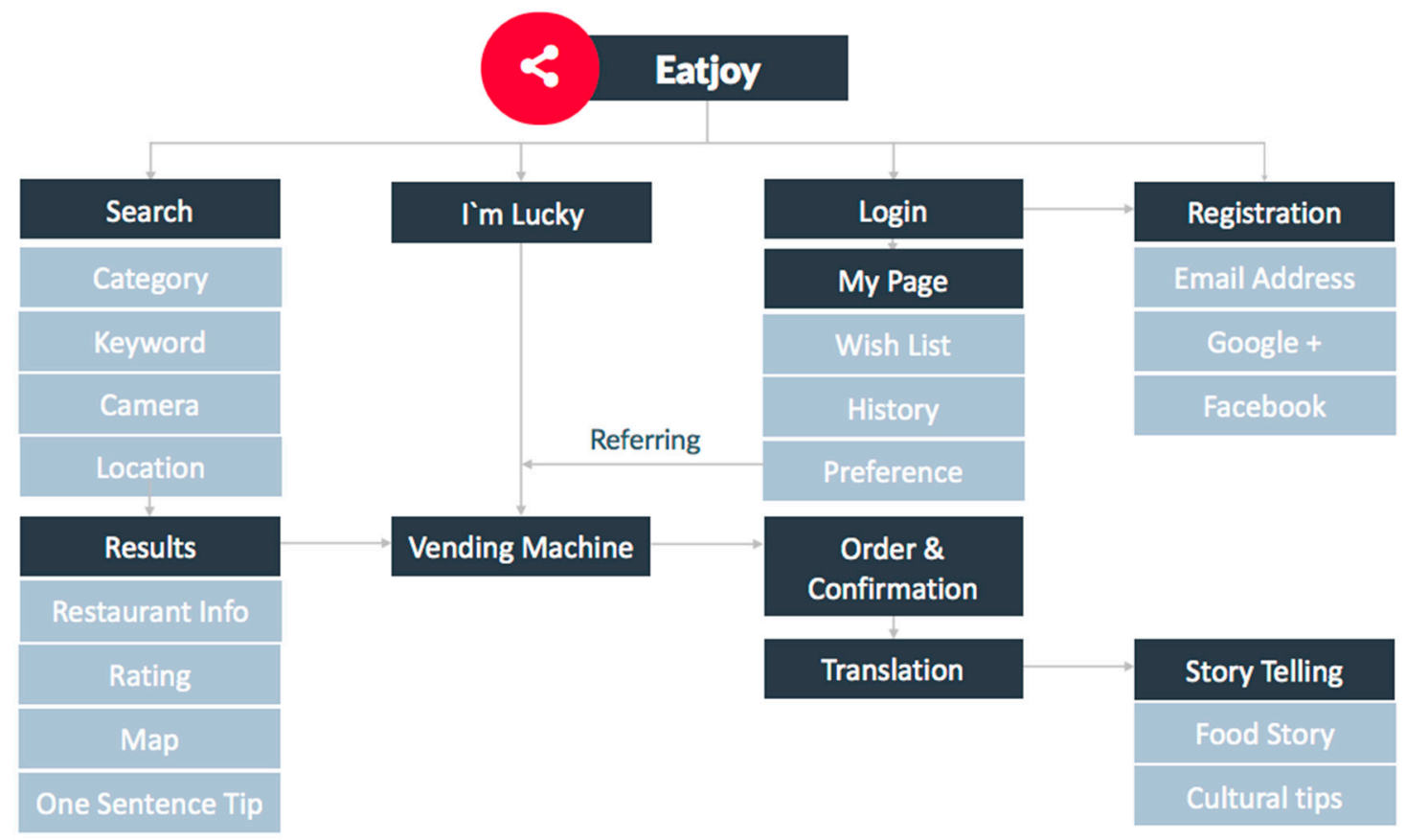

Figure 4. The information architecture of EATJOY.
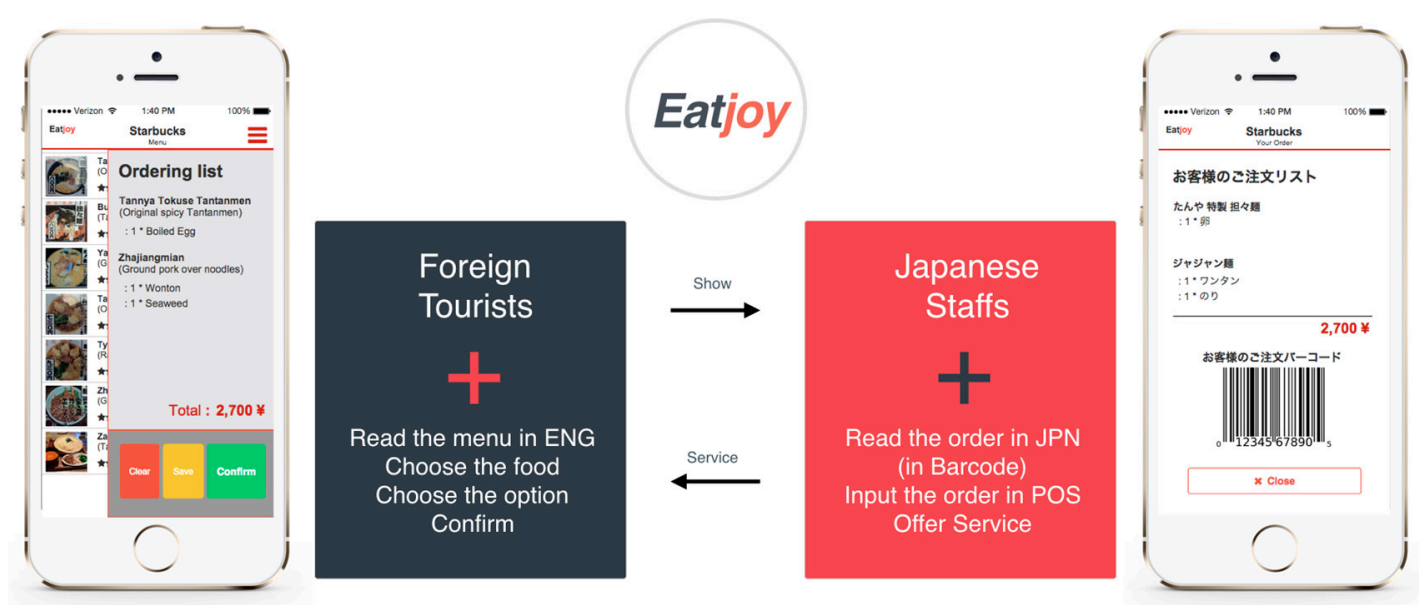

Figure 5. The main screens of EATJOY. 
The meaning of EATJOY is the fine-tuner that adjusts complex relations of socio-technical systems (people, behavior, structure and technology) in an optimal blend in a cultural context. By using EATJOY, tourists and local staffs can fully utilize their cultural advantage (i.e., Omotenashi culture) and values of experience by IT-enabled interactions.

\subsubsection{Demonstration and Evaluation}

This phase was iterated in two rounds-the first round is for demonstrating and examining the functionality and effectiveness of the initial artifact and exploring the potential problems for further improvements; and the second round is for evaluating how exactly the artifact supports a solution to the present tourism problems in Japan, based on the principles of the STS-based design framework.

In the first round, semi-structured interviews were made with the purpose of investigating users' opinion and testing the utility of the proposed artifact. The interviews were conducted in Roppongi area, Tokyo, Japan with eight users (i.e., three of the local staff and five foreign tourists). The team explained the design concept and showed the users how to work with the initial primitive prototype. After the initial demonstration and the utility test, the team could tentatively confirm the positive impact and benefits of the EATJOY mobile applications. Local staffs moderately agreed on the targeted problem (i.e., communication barriers, etc.) and expected benefits of the design concept in their working place. Foreign tourists agreed more strongly on the problem definition and the design concept, and even actively made several suggestions for improving the design concept. They expressed the convenience of using vending machine; some of the foreign tourists deliberately search for restaurants equipped with vending machines. However, they felt that, in this way, they miss the cultural interaction with the local staff. The team decided to repeat the design cycle to embrace the newly discovered problems and to improve the functionality and effectiveness of the proposed artifact.

In the second round, the EATJOY demo was developed based on the updated design concept. The design concept primarily aims to support communication, informational activities, and cultural instructions amongst tourism stakeholders in a form of mobile application. The following personas represent two stakeholders, and their journeys demonstrate the key features and functions of the artifact and how the artifact can provide solutions to the targeted problems:

Journey of Felix Schulze: Felix is a 20-year-old college student from Germany. He has just arrived in Japan as part of his Asian backpacking trip. He has plans to visit many of the typical tourist destinations, however he has a limited time in Japan. One of the main goals of this trip is to eat authentic Japanese foods. Thus, he wants to visit small-local Japanese restaurants rather than international franchises. He used famous tourism websites such as Lonely Planet and TripAdvisor to find restaurants; however, he is often disappointed that those places are mostly filled with foreign tourists, not local people; some reviews have not matched, concerning his personal preferences. Due to his limited Japanese skill, examining the menu in restaurants is challenging for him to understand what kind of food is served, without the English names or photos. Many times, he feels that he is missing the full Japanese experience when he does not understand the menu and tends to choose the most basic version of dishes. Sometimes, he hesitates to enter Japanese restaurants when there is no English menus or available information. After knowing about the functions and features of the EATJOY mobile application from other tourists in his hostel, he installed the app on his smartphone. He decided to give it a try. He opened EATJOY, and started searching restaurants by location. Then, on his screen, plenty of local restaurants were listing up, so he filtered them by the evaluation score to find the good ones easily. After considering for a few minutes, he decided which restaurant to visit, based on the menu, price and reviews. When arriving at the store front, he took a photo of the store sign to get the VM screen. Then, he chose the ramen menu, and gave his device to the local staff without delays. The local staff initially seemed nervous, but she smiled when receiving his phone. Through her body language (pointing out the screen, shaping her hand to " $X$ "), she informed that the menu that Felix ordered is not possible to provide because the restaurant had run out of ingredients. Felix easily understood what she explained, and changed the menu right away with the device, and confirmed the order with the staff. A few seconds after the order completion, he automatically received a story screen that contains the cultural story related to ramen. According to the story, making eating sounds in ramen stores is a polite manner, because that 
indicates satisfaction about taste of food and service. Felix followed the instructions, and the staff responded to his manner by her smiling.

Journey of Shiori Watanabe: Shiori is a 23-year-old female staff, working in Tatsu-ya ramen restaurant in Tokyo. She has been working there full-time for roughly a year. Due to the location of the store, it is quite rare to receive foreigners, and, when they do, she becomes really nervous and embarrassed over her low English ability. Once she tried to prepare the English menu for the foreign tourists, but the store received more complains about clerical errors and limited number of choices about new and seasonal menus due to difficulties in updating the menu regularly. She knows that several neighboring restaurants sometimes claim to the foreign customers that the store is full, to avoid speaking English in their service, whereas the manager of her store wants to have more customers and does not care whether they are Japanese or not. However, similar to Shiori, most of the staffs cannot speak English and need to learn. As usual, Shiori works in the restaurant, and the store is almost full with long queue, especially on the peak time (lunch time). She mainly takes the order and helps in serving food to the customers at the counter. During her work, she detected one foreign customer waiting in the queue, and she became so nervous. For a moment, she glanced backwards to the kitchen to find anyone who can help her, but all of the employees were busy. If she asked for help, they might have to stop their work to help her, and it will impact the effective operation of the kitchen. Finally, the foreign customer approached to the counter and suddenly handed over his mobile device to her. She looked at the device, and realized that the screen of the device contained his order in her local language. Since they ran out of the ingredients required for that dish, it was needed for her to inform him that his order is not possible now. Thanks to the initiation of the body-language communication by the foreign customer, she easily explained the situation through her body language (pointing out to the screen, shaping her hand to " $X$ ") as well. He easily understood, and changed the menu by touching the screen again. She was surprised, because the new order was from the seasonal menu that the old English-written menu for the did not contain. After confirmation of the order, she brightly returned thanks to him, and served the food. She glanced at him while he was eating, and could not help smiling because he expressed his satisfaction of food through his eating sound, exactly like the local customers.

By demonstrating the design concept, the project team could find that the artifact shows some support to solving the targeted communication problem. For instance, the EATJOY application embraces the vending machine metaphor and the stopgap behaviors that the stakeholders know well. It could assist effective interaction between foreign tourists and local staffs in service site; the artifact first helped releasing the emotional pressure and tensions of the tourists (i.e., the artifact provided the menu in multi-language with the time of preparation) and the tensions of the local staffs as well (i.e., the artifact shows the tourists' requests translated in the local language), which was a primary bottleneck of tourism service in social subsystem. Then, the artifact promoted quality of tourism experience by facilitating interaction (i.e., instead of eliminating the interaction, the artifact promoted trial of interaction with body languages), expanding the options for tourists (i.e., the artifact provided updated menu information, including seasonal and temporal menus), and instructing cultural context (i.e., the artifact provided cultural information related to the requested service after the interaction), so that tourists could enjoy moment of service usage with higher and various values of experience.

Based on the above demonstration, the final utility test was conducted with six participants (three local students and three foreign students) for the final evaluation purpose. To set the target context, participants were selected based on nationality, Japanese or English language proficiency, and the period of working in service industry or period of staying in Japan (Table 2).

Table 2. Demographic information of the utility test participants.

\begin{tabular}{ccccc}
\hline Test Set & Participant & Nationality & Language Proficiency & Relevant Experience \\
\hline \multirow{2}{*}{ Group 1 } & A & Japan & Japanese (native)/English (limited) & Working as part-timer for 2 years \\
& B & Mexico & Japanese (unable)/English (fluent) & Visiting Japan for 1 month \\
Group 2 & C & Japan & Japanese (native)/English (unable) & Working as part-timer for 3 years \\
& D & India & Japanese (limited)/English (native) & Visiting Japan for 1.5 year \\
Group 3 & E & Japan & Japanese (native)/English (limited) & Working as part-timer for 4 years \\
& F & China & Japanese (unable)/English (fluent) & Visiting Japan for 1 month \\
\hline
\end{tabular}


A test site was made similar to a local restaurant setting; and specific roles were given to each group of participants-Local staff roles to the Japanese participants, and foreign tourists roles to the foreign participants while testing two conditions: (a) without the design artifact; and (b) with design artifact (the final interactive prototype created by Axure RP Team Edition 8.0 (Axure Software Solutions, San Diego, USA)). Figure 6 shows the test site and the role playing activity.

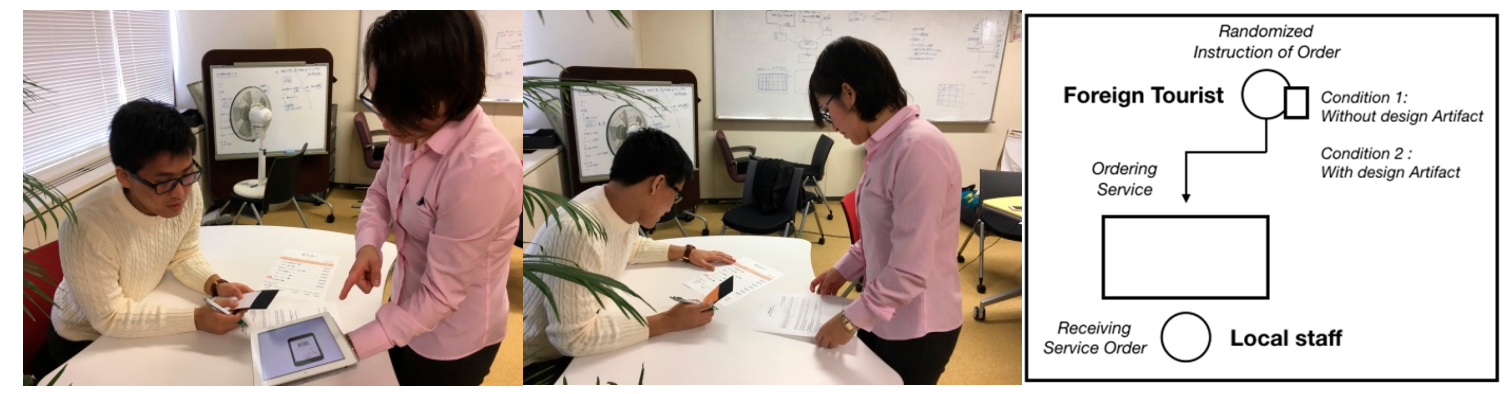

Figure 6. Utility test and its settings.

The utility test was conducted with three groups in two rounds to assess the effect of using the proposed design artifact. In the first test, local participants were asked to take and note a service order with calculating the total price; foreign participants were asked to enter the service site and complete the service order with randomized instruction of food without any IS assistance. In the second test, identical instruction was given to the local participants, but the foreign participants were asked to use the design artifact (EATJOY) during the service ordering process. After finishing the tests, integrity check was made to compare the local participants' notes with the given instructions and individual in-depth interviews (15 min each) were conducted with the participants, based on the STD model described in the previous section, to evaluate the effectiveness and the attained values of the design artifact (EATJOY) for tourism stakeholders. Table 3 summarizes the feedback of the local participants on the proposed design artifact. Table 4 summarizes the feedback of the foreign participants on the proposed design artifact in terms of its effect on their values of experience.

Table 3. Summary of the local participants' feedback on the proposed design artifact after the utility test.

\begin{tabular}{|c|c|}
\hline Easiness of Service Provision & Emotional Comfort \\
\hline $\begin{array}{l}\text { (A) I found the app very useful as it shows } \\
\text { the barcode and image with the translated order. } \\
\text { Using the app makes things very easy to the staff. } \\
\text { (C) I think that the app assist the service provision } \\
\text { process quite well, as it relieves the local staff from } \\
\text { desperate explanation. } \\
\text { (E) I felt that the service process finished very quickly } \\
\text { when using this app; the function that makes foreign } \\
\text { people able to order without speaking is very useful. }\end{array}$ & $\begin{array}{l}\text { (A) It would be so much thankful thing, if all } \\
\text { the foreign customers complete their order in efficient } \\
\text { way by bringing this app. } \\
\text { (C) I usually feel emotionally confounded toward } \\
\text { foreign people; by using the app, it gives me } \\
\text { emotional comfort. } \\
\text { (E) It is not comfortable to receive foreign customers } \\
\text { in busy times, as it generally takes more time. } \\
\text { This app emotionally comfortable, as we just need to } \\
\text { deliver the order shown on the screen. }\end{array}$ \\
\hline Comprehension toward customer & Motivation to additional interaction \\
\hline $\begin{array}{l}\text { (C) The app facilitates the order completion. } \\
\text { (E) It somehow helps in terms of accuracy of } \\
\text { receiving order. }\end{array}$ & (E) I can express more easily. \\
\hline
\end{tabular}


Table 4. Summary of the foreign participants' feedback on the proposed design artifact after the utility test.

\begin{tabular}{|c|c|}
\hline Functional Value & Social Value \\
\hline $\begin{array}{l}\text { (B) If such vending machine can be owned by tourist in advance } \\
\text { and offered in English description, it would be definitely more } \\
\text { helpful and functional. } \\
\text { (D) When newly coming here, I was always hesitated to order } \\
\text { from menus, as I don't know what I am going to get, the app is } \\
\text { useful as all the menu are provided in my native language; I can } \\
\text { order really fast; there is no uncertainty in the service. } \\
\text { (F) I like the app as the app gives detailed options, which makes } \\
\text { things easier. }\end{array}$ & $\begin{array}{l}\text { (B) Reviews created by local people on local } \\
\text { restaurants are valuable. It really works, even } \\
\text { though I do not understand the meaning of } \\
\text { the local reviews; but viewing the rating } \\
\text { and scores is very useful. }\end{array}$ \\
\hline Emotional Value & Epistemic Value \\
\hline $\begin{array}{l}\text { (B) If the tourist owns the menu on his own device, he may not } \\
\text { feel pressured during making his order. } \\
\text { (D) In my first visit to a Japanese restaurant, I had many } \\
\text { questions, since I almost knew nothing by that time. Having } \\
\text { longer conversations gives me some stress and pressure, as it } \\
\text { takes time of the waiting people behind me; By using the app, I } \\
\text { can understand things in advance, I can have enough time for } \\
\text { decision, and then order without such pressures. } \\
\text { (F) Before using the app, when there were lots of people behind } \\
\text { me, I became nervous, and I took much longer time to complete } \\
\text { order. This feeling was eliminated by using the app. }\end{array}$ & $\begin{array}{l}\text { (B) I feel that interactions with local staff, } \\
\text { vending machine, or this app are all pretty } \\
\text { much same for me. } \\
\text { (D) If the exploration is the main purpose, my } \\
\text { motivation is bit different. In the case of using } \\
\text { traditional vending machine, there is no human } \\
\text { interaction at all, so in that sense, it is better to } \\
\text { use the app which at least has some degree of } \\
\text { interaction. }\end{array}$ \\
\hline
\end{tabular}

In terms of value for local service staff, most local participants expressed positive opinions toward the proposed design artifact, EATJOY. Particularly, all participants strongly agreed on the effectiveness and efficiency of the artifact since it provides "Easiness of service provision" and "Emotional comfort". Some of participants agreed on the effectiveness of the artifact in other aspects such as "Comprehension toward customer" and "Motivation to additional interaction".

With respect to the values of experience for the foreign tourists, most foreign participants displayed positive opinions toward the proposed design artifact "EATJOY". All the participants strongly agreed on the positive effect of the artifact in supporting "Functional value" and "Emotional value", while partially agreed on the positive effect of the artifact in supporting "Social value" and "Epistemic value".

To sum up, EATJOY displayed significant support of the target problems; the dysfunctional communication between local service staffs and foreign tourists during the service process. For the local Japanese staff, it primarily supported clearer communication with the tourists, so that it could help them achieving easier service provision and having more emotional comfort, which have been considered as a primary obstacle for the Omotenashi culture. Based on this support, some participants expressed some potential change toward igniting the Omotenashi culture (i.e., motivation to additional interaction). For the foreign tourists, the design artifact significantly generated functional values and emotional values and partially generated social values and epistemic values during the service experience. These result also shows some degree of satisfaction toward creating multi-dimensional values of experience in tourism, which is one of the main objectives of this work.

\subsubsection{Communication}

As part of the "Communication" phase of DSR paradigm, the initial description of this project was presented in a well-known academic conference. Based on the feedbacks from the audience, the team enhanced the evaluation by adding one more test round with closely linkage with STS-based design framework. 


\section{Contributions and Implications}

This research reinforces the views on designing smart tourism systems in Socio-technical systems theory, the essence of this design is: (1) joint-optimization of subsystems; and (2) humanistic and multi-group perspectives. This view has been operationalized in the context of designing a service-assisting system for local staffs and foreign customers in the tourism industry. In the sections below, we discuss generic and specific theoretical and practical implications from our reflections, as well as some proposed future research directions.

\subsection{Theoretical Implications}

The paper fills a gap in the design of Information Systems in smart tourism domain. Despite scholars highlighted the importance of tourism experience in designing tourism systems, only limited number of works addressed how to design and evaluate such systems. Based on the research questions, possible design elements and relevant values for stakeholders in tourisms were clarified and synthesized into design framework based on a view of socio-technical systems theory. An actual design of artifact was conducted via the proposed framework in the Japanese tourism context to evaluate its effectiveness.

The contribution of this study to the Smart Tourism in IS can be condensed into three main directions. First, this study proposed a new design framework in designing experience-centered tourism systems as sustainable and smart tourism systems. Thus far, most of the literature on IS was focusing on technical subsystems and expected the systems to enrich the tourists' experiences. In addition, there is a lack of works that consider systems value from tourists' experience point of view. In this study, based on perspective of socio-technical systems theory, elements and interactions were clarified to follow multi-dimensional values for primary stakeholders with two primary STS principles-joint-optimization view of subsystems, and humanistic and multi-group perspective. Second, in design science, providing situated implementation of the artifact is considered as the first step of design model, framework, and theory. In this study, STD model and a tourism information were proposed and synthesized, based on tourism problems and the proposed views and principles from STS theory. The result of evaluation displays functionality and effectiveness of the model and the artifact toward discovered problems in tourism; for instance, the model demonstrated its value for designing successful, smart, and sustainable tourism systems via proposing significant design artifact; the design artifact also proved its functionality in sustainable tourism via showing potential ignition of Omotenashi culture with improvement in service provision factors and tourists' values of experience in tourism. Third, this study highlighted the potential roles of IS in tourism by presenting a tourist-friendly application on service site. In prior studies, most roles of IS in tourism have been mainly concentrated on information searching and processing. Through this study, IS take more diversified roles: communication supportive, decision supportive, and cultural instructive.

\subsection{Practical Implications}

This work also provides practical contribution in two folds. First, this study provides a direction of design on tourism experience-centered systems. Thus far, despite the importance of experience in tourism, there has been lack of guidelines or case studied for the practitioners on designing such systems. The proposed system provides the core elements and steps of designing by elucidating our design project "The Digital Omotenashi". Second, this study could give and effective solution for real problems in Japanese tourism context (i.e., tourists' limited values of tourism experience, and unrealized Omotenashi cultural impact) in real situations and by synthesizing a design artifact, EATJOY. The evaluation phase of the design process showed the evidence of the capability of the proposed artifact towards real-world problems. 


\section{Limitations and Future Research}

In this study, a Smart Tourism Design model (STD model) was proposed and a supporting design artifact (EATJOY) was synthesized with displaying design process and functionality and features based on DSR paradigm.

However, there are some limitations in this study. First, the evaluation was made in a relatively subjective way, based on interviews and qualitative analysis. Although the DSR paradigm approves the usage of qualitative evaluation, especially when the outcome factors are difficult to quantify (e.g., culture, experience, and perceived value), a more rigorous systematic approach may be required for further evaluation to prove the value of the proposed design artifact in scientific sense. Second, while the observations were taken from real-life study fields, the utility test was made in artificial conditions as a lab experiment. Despite DSR paradigm suggests artificial evaluation as a method with lower risk, lower costs and quicker prototyping; further evaluation in naturalistic conditions may help the team to improve the design artifact to be more suitable and responsive to real situations.

Acknowledgments: We wish to thank project participants and Senoo Dai, for their valuable comment and advice.

Author Contributions: Chaeyoung Lim and Jaehyun Park conceived, designed and performed overall research project; during the project, Chaeyoung Lim performed field work, design, and implementation, and test of design artifact; Jaehyun Park, as project advisor and instructor, provided guidance on design and research work throughout entire project period. Noha Mostafa, as co-author, contributed in writing some part of paper with some critical inputs.

Conflicts of Interest: The authors declare no conflict of interest.

\section{References}

1. Buhalis, D.; Law, R. Progress in information technology and tourism management: 20 years on and 10 years after the internet-The state of etourism research. Tour. Manag. 2008, 29, 609-623. [CrossRef]

2. Buhalis, D.; Amaranggana, A. Smart tourism destinations. In Information and Communication Technologies in Tourism 2014; Springer: Cham, Switzerland, 2013; pp. 553-564.

3. Gretzel, U.; Sigala, M.; Xiang, Z.; Koo, C. Smart tourism: Foundations and developments. Electron. Mark. 2015, 25, 179-188. [CrossRef]

4. Miah, S.J.; Vu, H.Q.; Gammack, J.; McGrath, M. A big data analytics method for tourist behaviour analysis. Inf. Manag. 2017, 54, 771-785. [CrossRef]

5. Fuchs, M.; Höpken, W.; Lexhagen, M. Big data analytics for knowledge generation in tourism destinations-A case from sweden. J. Destin. Mark. Manag. 2014, 3, 198-209. [CrossRef]

6. Xiang, Z.; Wang, D.; O'Leary, J.T.; Fesenmaier, D.R. Adapting to the internet: Trends in travelers' use of the web for trip planning. J. Travel Res. 2015, 54, 511-527. [CrossRef]

7. Tussyadiah, I.P.; Fesenmaier, D.R.; Yoo, Y. Tracking tourists' spatiotemporal experiences as collective narratives of an urban destination. In Proceedings of the TTRA Annual Conference, Philadelphia, PA, USA, 15-17 June 2008.

8. Yoo, Y.; Tussyadiah, I.P.; Fesenmaier, D.R.; Saari, T.; Tjostheim, I. Emergent distributed narratives in spatiotemporal mobility: An exploratory study on mobile 2.0 services. In Proceedings of the 41st Annual Hawaii International Conference on System Sciences, Washington, DC, USA, 7-10 January 2008; IEEE: Washington, DC, USA; p. 85.

9. Tussyadiah, I.P.; Fesenmaier, D.R.; Yoo, Y. Designing interactions in tourism mediascape-Identification of patterns for mobile 2.0 platform. Inf. Commun. Technol. Tour. 2008, 2008, 395-406.

10. Tussyadiah, I.P.; Park, S.; Fesenmaier, D.R. Assessing the effectiveness of consumer narratives for destination marketing. J. Hosp. Tour. Res. 2011, 35, 64-78. [CrossRef]

11. Bostrom, R.P.; Heinen, J.S. Mis problems and failures: A socio-technical perspective, part ii: The application of socio-technical theory. MIS Q. 1977, 1, 11-28. [CrossRef]

12. Clegg, C.W. Sociotechnical principles for system design. Appl. Ergon. 2000, 31, 463-477. [CrossRef]

13. Gretzel, U.; Yoo, K.H. Use and impact of online travel reviews. Inf. Commun. Technol. Tour. 2008, 2008, 35-46.

14. Huang, C.D.; Goo, J.; Nam, K.; Yoo, C.W. Smart tourism technologies in travel planning: The role of exploration and exploitation. Inf. Manag. 2017, 54, 757-770. [CrossRef] 
15. Buhalis, D.; Amaranggana, A. Smart tourism destinations enhancing tourism experience through personalisation of services. In Information and Communication Technologies in Tourism 2015; Springer: Cham, Switzerland, 2015; pp. 377-389.

16. Chung, N.; Koo, C.; Lee, K. Assessing the impact of mobile technology on exhibition attendees' unplanned booth visit behaviour. Sustainability 2017, 9, 884. [CrossRef]

17. Garau, C. Perspectives on cultural and sustainable rural tourism in a smart region: The case study of marmilla in sardinia (italy). Sustainability 2015, 7, 6412-6434. [CrossRef]

18. Hunter, W.C.; Chung, N.; Gretzel, U.; Koo, C. Constructivist research in smart tourism. Asia Pac. J. Inf. Syst. 2015, 25, 105-120.

19. Um, S.; Chon, K.; Ro, Y. Antecedents of revisit intention. Ann. Tour. Res. 2006, 33, 1141-1158. [CrossRef]

20. Som, A.P.M.; Badarneh, M.B. Tourist satisfaction and repeat visitation; toward a new comprehensive model. Int. J. Hum. Soc. Sci. 2011, 6, 38-45.

21. Hunter, C. Sustainable tourism as an adaptive paradigm. Ann. Tour. Res. 1997, 24, 850-867. [CrossRef]

22. Jennings, G.; Lee, Y.-S.; Ayling, A.; Lunny, B.; Cater, C.; Ollenburg, C. Quality tourism experiences: Reviews, reflections, research agendas. J. Hosp. Mark. Manag. 2009, 18, 294-310. [CrossRef]

23. Williams, P.; Soutar, G.N. Dimensions of Customer Value and the Tourism Experience: An Exploratory Study. In Australian and New Zealand Marketing Academy Conference; Queensland, Australia, 2000; 28, pp. 1415-1421. Available online: http://pandora.nla.gov.au/pan/25410/20020805-0000/130.195.95.71_ 8081/www/ANZMAC2000/home.htm (accessed on 23 November 2017).

24. Cravens, D.W.; Holland, C.W.; Lamb, C.W.; Moncrief, W.C. Marketing's role in product and service quality. Ind. Mark. Manag. 1988, 17, 285-304. [CrossRef]

25. Chang, T.-Z.; Wildt, A.R. Price, product information, and purchase intention: An empirical study. J. Acad. Mark. Sci. 1994, 22, 16-27. [CrossRef]

26. Bolton, R.N.; Drew, J.H. A multistage model of customers' assessments of service quality and value. J. Consum. Res. 1991, 17, 375-384. [CrossRef]

27. Babin, B.J.; Darden, W.R.; Griffin, M. Work and/or fun: Measuring hedonic and utilitarian shopping value. J. Consum. Res. 1994, 20, 644-656. [CrossRef]

28. Sheth, J.N.; Newman, B.I.; Gross, B.L. Why we buy what we buy: A theory of consumption values. J. Bus. Res. 1991, 22, 159-170. [CrossRef]

29. Kaasinen, E. User Acceptance of Mobile Services: Value, Ease of Use, Trust and Ease of Adoption; VTT Technical Research Centre of Finland: Espoo, Finland, 2005.

30. Kettinger, W.J.; Smith, J. Understanding the consequences of information systems service quality on is service reuse. Inf. Manag. 2009, 46, 335-341. [CrossRef]

31. Neuhofer, B.; Buhalis, D.; Ladkin, A. Technology as a catalyst of change: Enablers and barriers of the tourist experience and their consequences. In Information and Communication Technologies in Tourism 2015; Springer: Cham, Switzerland, 2015; pp. 789-802.

32. Boes, K.; Buhalis, D.; Inversini, A. Conceptualising smart tourism destination dimensions. In Information and Communication Technologies in Tourism 2015; Springer: Cham, Switzerland, 2015; pp. 391-403.

33. Liu, J.; Ma, Y. The perceptual differences among stakeholders in the tourism supply of xi'an city, China. Sustainability 2017, 9, 214. [CrossRef]

34. Ivanov, S.H.; Webster, C.; Berezina, K. Adoption of robots and service automation by tourism and hospitality companies. In Proceedings of the INVTUR Conference, Aveiro, Portugal, 17-19 May 2017.

35. Yim, J. Review of the kiosk related research results. Adv. Sci. Technol. Lett. 2015, 85, 51-54.

36. Khan, G.F. Social media-based systems: An emerging area of information systems research and practice. Scientometrics 2013, 95, 159-180. [CrossRef]

37. Manz, C.C.; Stewart, G.L. Attaining flexible stability by integrating total quality management and socio-technical systems theory. Org. Sci. 1997, 8, 59-70. [CrossRef]

38. Xing, K.; Ness, D.; Lin, F.-R. A service innovation model for synergistic community transformation: Integrated application of systems theory and product-service systems. J. Clean. Prod. 2013, 43, 93-102. [CrossRef]

39. Walker, G.H.; Stanton, N.A.; Salmon, P.M.; Jenkins, D.P. A review of sociotechnical systems theory: A classic concept for new command and control paradigms. Theor. Issues Ergon. Sci. 2008, 9, 479-499. [CrossRef]

40. Gregor, S.; Jones, D. The anatomy of a design theory. J. Assoc. Inf. Syst. 2007, 8, 312. 
41. Peffers, K.; Tuunanen, T.; Rothenberger, M.A.; Chatterjee, S. A design science research methodology for information systems research. J. Manag. Inf. Syst. 2007, 24, 45-77. [CrossRef]

42. Hevner, V.A.R.; March, S.T.; Park, J.; Ram, S. Design science in information systems research. MIS Q. 2004, 28, 75-105. [CrossRef]

43. Ota, T.; Takeda, T. The analysis of the movement of experienced and inexperienced persons in japanese bowing. In Proceedings of the First International Conference on Human and Social Analytics (HUSSO 2015), St. Julians, Malta, 11-16 October 2015.

44. Al-alsheikh, A. The origin of japanese excellent customer service. Stud. Bus. Acc. 2014, 8, $23-42$.

45. Joraku, M. Omotenashi-The Heart of Japanese Hospitality. Retrieved from Japan Products. Available online: http:/ /japan-product/.com/omotenashi (accessed on 22 November 2017).

46. Yi, Z. Introducing Omotenasai'to the World: Challenges to Japanese Customer Service in a Cross-Cultural Setting. Transcult. Manag. Review. 2016, 13, 47-63. Available online: http:/ /jairo.nii.ac.jp/0025/00041280 (accessed on 22 November 2017).

(C) 2017 by the authors. Licensee MDPI, Basel, Switzerland. This article is an open access article distributed under the terms and conditions of the Creative Commons Attribution (CC BY) license (http://creativecommons.org/licenses/by/4.0/). 